\title{
CHARACTERIZATION OF HYDRAULIC PIPES BURYED IN URBAN AREAS BY THE GPR
} METHOD

Deisy Grazielle Ferreira Nunes, Maria Vitória dos Santos Fernandes, Hersília de Andrade e Santos, Marcos de Paulo

Ramos, Thiago Pena Bortone, Tathiana Rodrigues Caetano, Rachel Jardim Martini, CEFET-MG

Copyright 2021, SBGf - Sociedade Brasileira de Geofísica.

This paper was prepared for presentation during the $17^{\text {th }}$ International Congress of the Brazilian Geophysical Society held in Rio de Janeiro, Brazil, $16-19$ August 2021.

Contents of this paper were reviewed by the Technical Committee of the $17^{\text {th }}$ International Congress of the Brazilian Geophysical Society and do not necessarily represent any position of the SBGf, its officers or members. Electronic reproduction or storage of any part of this paper for commercial purposes without the written consent of the Brazilian Geophysical Society is prohibited.

\begin{abstract}
Leaks in water supply and sewage collection systems are notable problems in Brazil. The scarcity of resources, the difficulty of supplying drinking water and an adequate sewage collection network can cause leaks in the subsoil causing environmental impacts both with the contamination of the soil and in the excavation of it to contain possible disasters. With the growth of civil construction and the need for monitoring techniques, the use of non-destructive tests, such as GPR (Ground Penetrating Radar), has become increasingly attractive.
\end{abstract}

This work is a theoretical study that aims to characterize hydraulic pipes buried in an urban context, using the GPR. As a methodology for this theoretical study, SciELO, UFPA Repository and Google Scholar databases were used. After research with the keywords "GPR", "Hydraulic Pipes", "Environmental Impacts", the results were analyzed and a total of 08 bibliographic references were published, published in the period from 2006 to 2020. The articles were analyzed in order to contextualize the efficiency of using this method in the characterization of urban environments.

The GPR, a geophysical technique based on the reflection of electromagnetic waves at high frequency, has been used to locate buried objects, lay out structures, shallow geological aspects of the subsurface, and has been gaining visibility in several areas of civil engineering. The functioning of the GPR is based on the release of a magnetic pulse that reaches an area of geological interaction that secretes the different electromagnetic properties, the electromagnetic waves are divided, with one fraction undergoing refraction and diffraction and the other fraction continues to propagate until it is fully absorbed by the medium. The study shows that the frequencies of the most widely used antennas are $100 \mathrm{MHz}$, and $500 \mathrm{MHz}$, having a better performance with 200 $\mathrm{MHz}$ antennas. It is also suggested, due to the accuracy of the data and greater penetration power, the use of combined techniques, such as inductive electromagnetic method and chemical analysis.

After studying the literature, we concluded that the GPR method is effective for analyzing hydraulic pipes buried in an urban context, being of great value for checking, maintaining and expanding the system. Even to aid in the determination of the material used, through the characterization of the piping system, despite the existence of possible interference due to the properties of the soil and the piping itself. 